\title{
Reply to Rheumatologists' perspective on coronavirus disease 19: is heparin the dark horse for COVID-19?
}

\author{
Sakir Ahmed ${ }^{1}$ (i) $\cdot$ Prajna Anirvan ${ }^{2}$ (D) \\ Received: 18 April 2020 / Revised: 18 April 2020 / Accepted: 1 May 2020 / Published online: 9 May 2020 \\ (C) International League of Associations for Rheumatology (ILAR) 2020
}

We read with interest the review on pharmacological treatments for COVID-19 [1]. The authors have quite succinctly presented all major therapies being attempted. In this regard, we would like to point out that heparin is also another candidate drug with proven mortality benefit in a subset of patients [2]. Disseminated intravascular coagulation (DIC) is a known complication of COVID-19 and pulmonary autopsies from deceased patients diagnosed with COVID-19 have shown multiple microthrombi. The use of heparin for more than 7 days in 99 patients led to reduced mortality in those with sepsis-induced coagulopathy (SIC) score $\geq 4$ or Ddimer $>6$-fold of upper limit of normal [2]. Heparin has multiple possible mechanisms of action which may support its use for COVID-19.

SARS coronavirus strain HSR1 multiplication can be directly inhibited by heparin as evidenced by reduction of viral plaques by $50 \%$ on addition of heparin to Vero cell cultures [3]. One of the mechanisms of inhibition of cellular entry of SARS coronavirus is via lactoferrin binding [4]. It has shown that even the spike protein

Sakir Ahmed

sakir005@gmail.com

Prajna Anirvan

prajnaanirvan@gmail.com

1 Department of Clinical Immunology \& Rheumatology, Kalinga Institute of Medical Sciences (KIMS), KIIT University, Bhubaneswar 751024, India

2 Department of Gastroenterology, Sriram Chandra Bhanj Medical College and Hospital, Cuttack 753007, India
S1 of the SARS-CoV-2 undergoes a conformational change on exposure to heparin [5]. Thus, heparin might inhibit cellular entry of the virus. This mechanism is likely to be more important during the early phases of the disease.

SARS-CoV-2 entry into a cell via the ACE2 receptor leads to shedding of this receptor [6]. We hypothesize that this predisposes to thrombosis. ACE2 normally cleaves bradykinin, and thus, low ACE2 causes bradykinin accumulation that may accelerate thrombosis. The knockout of bradykinin receptor B2 can prevent thrombosis in a murine model [7]. Also, ACE2 levels are found to be low in pulmonary thromboembolism.

The reduced ACE2 level increases angiotensin as well as aldosterone levels. Angiotensin can activate prothrombin leading to a procoagulant state [8]. Furthermore, RAAS (renin-angiotensin-aldosterone system) activation is linked to thrombosis by multiple mechanisms [9]. Therefore, ACE2 downregulation by SARS-CoV-2 may lead to enhanced thrombosis. In addition to its anticoagulant effects, heparin can also abrogate the adverse effects of RAAS activation as shown in mouse cardiomyocytes [10].

The potential mechanisms of action of heparin in COVID19 are represented diagrammatically in Fig. 1.

To summarize, SARS-CoV-2 can possibly activate the RAAS axis via ACE2 shedding and promote thrombosis. Heparin may prove to be beneficial by inhibiting viral entry into cells and antagonizing RAAS activation in addition to exerting its anti-coagulation effects in the aftermath of severe inflammation and SIC. Therefore, the optimal timing of administration of heparin along with the predictors of benefit should be explored in the confines of randomized or at least pragmatic trials. 


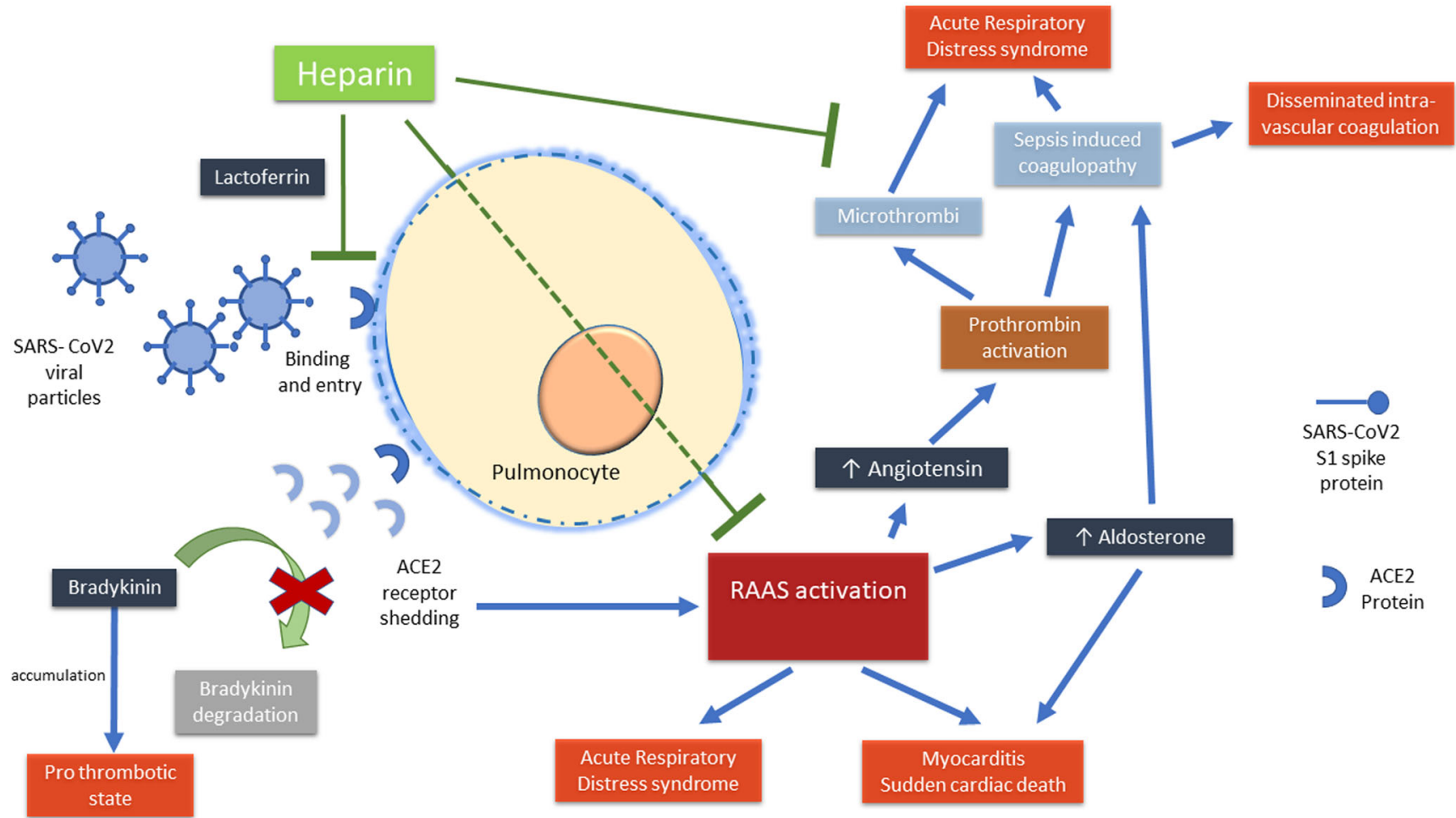

Fig. 1 Potential mechanisms of action of heparin in COVID-19. SARS-CoV-2, severe acute respiratory syndrome coronavirus 2; ACE2, angiotensinconverting enzyme 2; RAAS, renin-angiotensin-aldosterone system

Author contributions SA and PA conceptualized the letter. SA drafted the manuscript and it was critically revised by PA. All the authors who have approved the final manuscript take full responsibility for the contents of the manuscript.

\section{Compliance with ethical standards}

Disclosures None.

Ethics clearance This perspective does not come under the purview of an ethics review.

\section{References}

1. Misra DP, Agarwal V, Gasparyan AY, Zimba O (2020) Rheumatologists' perspective on coronavirus disease 19 (COVID-19) and potential therapeutic targets. Clin Rheumatol. https://doi.org/10.1007/s10067-020-05073-9

2. Tang N, Bai H, Chen X, Gong J, Li D, Sun Z (2020) Anticoagulant treatment is associated with decreased mortality in severe coronavirus disease 2019 patients with coagulopathy. J Thromb Haemost. https://doi.org/10.1111/jth.14817

3. Vicenzi E, Canducci F, Pinna D, Mancini N, Carletti S, Lazzarin A, Bordignon C, Poli G, Clementi M (2004) Coronaviridae and SARS-associated coronavirus strain HSR1. Emerg Infect Dis 10(3):413-418. https://doi.org/10.3201/eid1003.030683

4. Lang J, Yang N, Deng J, Liu K., Yang P., Zhang G., Jiang C. Inhibition of SARS pseudovirus cell entry by lactoferrin binding to heparan sulfate proteoglycans. PLoS One 2011;6(8):e23710. doi: https://doi.org/10.1371/journal.pone.0023710
5. Mycroft-West C, Su D, Elli S, et al. (2020) The 2019 coronavirus (SARS-CoV-2) surface protein (Spike) S1 receptor binding domain undergoes conformational change upon heparin binding. bioRxiv 971093. doi:https://doi.org/10.1101/2020.02.29.971093

6. Vaduganathan M, Vardeny O, Michel T, McMurray JJV, Pfeffer MA, Solomon SD (2020) Renin-angiotensin-aldosterone system inhibitors in patients with Covid-19. N Engl J Med. https://doi.org/ 10.1056/NEJMsr2005760

7. Shariat-Madar Z, Mahdi F, Warnock M, Homeister JW, Srikanth S, Krijanovski Y, Murphey LJ, Jaffa AA, Schmaier AH (2006) Bradykinin B2 receptor knockout mice are protected from thrombosis by increased nitric oxide and prostacyclin. Blood. 108(1): 192-199. https://doi.org/10.1182/blood-2006-01-0094

8. Ekholm M, Kahan T, Jörneskog G, Brinck J, Wallén NH (2015) Haemostatic and inflammatory alterations in familial hypercholesterolaemia, and the impact of angiotensin II infusion. J ReninAngiotensin-Aldosterone Syst. https://doi.org/10.1177/ 1470320315575848

9. Fraga-Silva RA, Da Silva DG, Montecucco F et al (2012) The angiotensin-converting enzyme 2/angiotensin-(1-7)/Mas receptor axis: a potential target for treating thrombotic diseases. Thromb Haemost 108(6):1089-1096. https://doi.org/10.1160/TH12-060396

10. Akimoto H, Ito H, Tanaka M, Adachi S, Hata M, Lin M, Fujisaki H, Marumo F, Hiroe M (1996) Heparin and heparan sulfate block angiotensin II-induced hypertrophy in cultured neonatal rat cardiomyocytes. A possible role of intrinsic heparin-like molecules in regulation of cardiomyocyte hypertrophy. Circulation. 93(4): 810-816. https://doi.org/10.1161/01.cir.93.4.810

Publisher's note Springer Nature remains neutral with regard to jurisdictional claims in published maps and institutional affiliations. 